\title{
Volatility spillovers for stock returns and exchange rates of tourism firms in Taiwan
}

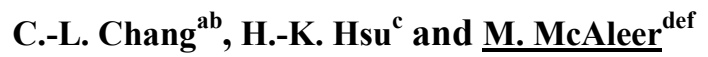 \\ ${ }^{a}$ Department of Applied Economics, National Chung Hsing University, Taiwan. \\ ${ }^{b}$ Department of Finance, National Chung Hsing University, Taiwan. \\ ${ }^{c}$ Department of Finance and Banking, National Pingtung Institute of Commerce, Taiwan \\ ${ }^{d}$ Department of Quantitative Finance,National Tsing Hua University, Hsinchu, Taiwan \\ ${ }^{e}$ Econometric Institute, Erasmus School of Economics, Erasmus University Rotterdam, The Netherlands. \\ ${ }^{f}$ Tinbergen Institute, The Netherlands \\ Email: michael.mcaleer@gmail.com
}

\begin{abstract}
This paper examines the size effects of volatility spillovers for firm performance and exchange rates with asymmetry in the Taiwan tourism industry. The analysis is based on two conditional multivariate models, BEKK-AGARCH and VARMA-AGARCH, in the volatility specification. Daily data from 1 July 2008 to 29 June 2012 for 999 firms are used, which covers the Global Financial Crisis. The empirical findings indicate that there are size effects on volatility spillovers from the exchange rate to firm performance. Specifically, the risk for firm size has different effects from the three leading tourism sources to Taiwan, namely USA, Japan, and China. Furthermore, all the return series reveal quite high volatility spillovers (at over sixty percent) with a one-period lag. The empirical results show a negative correlation between exchange rate returns and stock returns. However, the asymmetric effect of the shock is ambiguous, owing to conflicts in the significance and signs of the asymmetry effect in the two estimated multivariate GARCH models. The empirical findings provide financial managers with a better understanding of how firm size is related to financial performance, risk and portfolio management strategies that can be used in practice.
\end{abstract}

Keywords: Tourism, Size effects, Small-firm effects, Financial performance, Spillover effects, MGARCH, VARMA, BEKK 


\section{INTRODUCTION}

Taiwan, just across the straits from mainland China, is the only island bisected by the Tropic of Cancer in East-Asia. Rich in tourism resources, Formosa, or "Beautiful Island", is how the Portuguese viewed Taiwan when they sighted the untouched green island in the $16^{\text {th }}$ Century. The majority of people in Taiwan widely speak Minnan (the Southern Chinese dialect) as many Taiwanese trace their lineage from the southern part of China. Two of the most popular foreign languages in Taiwan are Japanese and English, due to the Japanese occupation of Taiwan during 1895-1945, and the English curriculum for high school students.

From 2008 to 2011, approximately 5 million inbound tourists visited Taiwan annually. With close links in cultural exchange, bilateral trade and economic development, the leading inbound arrival sources to Taiwan are China, Japan, and USA, which account for over half (averaging nearly 54\%) of inbound tourist arrivals annually during 2008-2011. In 2011, the growth of inbound visitors from these three leading tourist arrival sources was $9.41 \%, 19.87 \%$, and $4.27 \%$ from China, Japan and the USA, respectively, as compared with the previous year.

The travel and tourism (T\&T) sector, as a driver of economic growth, can stimulate GDP growth through jobs and enterprise creation, and provide significant foreign exchange revenues. The Government of Taiwan takes the tourism industry seriously, especially as the Global Financial Crisis of 2008-2009 severely cut Taiwan's exports. In May 2009, the government proposed that the tourism industry is a core and bellwether industry among the six key emerging industries, namely biotechnology, green energy, high-end (highquality) agriculture, medicine and health care, and cultural and creation industry, as the role of the tourism industry is to connect the six key emerging industries .

A series of major investments in the tourism industry are expected to expand the tourism sector significantly, such as an amendment to the "Best of Taiwan Tourism Development Plan" in April 2009. The plan is intended to create about US\$2,195 million in tourism revenues, add 437 thousand jobs, attract about US\$833 million in private investment, and bring at least 10 major international hotel chains to Taiwan from 2009 through to 2013.

Moreover, the government approved a constitutional amendment to Tourism Policies in 2012, containing implementations of the "Project Vanguard for Excellence in Tourism (2009-2014)", the "Medium-term Plan for Construction of Major Tourist Sites (2012-2015)", and the "2012-2013 Tourism Promotional Focus" under the principles of sustainability, quality, amity, life, and diversity. These principles involve the advancement of balanced development of regional economies and tourism, and optimization of the lives of local residents and the quality of travel. Above all, the Government of Taiwan regards the promotion of the tourism industry is high on the agenda.

The number of visitor arrivals exceeded 6 million in 2011, according to the Tourism Bureau in Taiwan. Visitor expenditures in Taiwan also experienced a rapid growth of $26.91 \%$ over the previous year. Historically, from 1991 to 2011, the visitor expenditure growth rate in Taiwan averaged $10.32 \%$, reaching an all-time high of $27.92 \%$ in 2010 , and a record low of $-6.44 \%$ in 1997 , excluding the $2002-2004$ years of SARS in Asia. For the period 2008-2010, the growth in annual visitor expenditures in Taiwan was $13.85 \%$ in $2008,14.82 \%$ in 2009 , and $27.92 \%$ in 2010 .

However, as the result of the Global Financial Crisis in 2009-2009, a still ongoing economic downturn, the economic uncertainty with high unemployment in Europe, Japan, and the USA has had adverse effects on the inbound tourism demand to Taiwan. Furthermore, in 2012, a series of new currency trading events occurred, such as direct trading of the Chinese Yuan against the Japanese Yen (on 1 June 2012), without using the U.S. dollar as an intermediate currency, other direct trade planning between the Chinese Yuan and Australian dollar, as well as the Chinese Yuan and New Taiwan dollar.

Since 2008, China, the world's second-largest economy ahead of Japan since 2010, has signed currency swap agreements with many countries, including the Republic of Korea and Malaysia. China's agenda of gradually making the Chinese Yuan a reserve currency has fostered trade tensions with the USA, and is expected to result in a significant impact on international money markets, especially in Asia.

Little is known about volatility spillovers between exchange rate returns and firm performance in the tourism industry, especially a comparison of the spillovers according to firm size. Firm size can be important in terms of evaluating performance, as discussed in the Industrial Organization literature. Previous research has shown that exchange rates have a significant effect on the tourism market, especially on international tourist arrivals, tourism costs, tourism competition, firm's earnings, relative purchasing power between the domestic and 
foreign countries, and the long term memory by tourists of such shocks over time. As shown in previous research, the exchange rate is an important factor of earnings for the tourism industry.

Moreover, exchange rate fluctuations dominate the overall impact on the tourism price of the tourism industry over time. From the financial risk management perspective, organizing a portfolio management strategy will become more important for Taiwan tourism industry over time. In particular, the intensity of fluctuating impacts from exchange rates to the tourism industry might vary with the firm size.

The primary purpose of the empirical section in this paper is to examine the performance of tourism firms as they relate to firm size. For the reasons given above, it is worth exploring the information about risk spillovers from exchange rates to tourism performance, as well as examining how the tourism industry responds to changes in exchange rates for tourism industry firms of different sizes.

\section{HOW TO EVALUATE THE SPILLOVER EFFECT AND SIZE EFFECT}

In this section we describe the spillover effect and size effect, as well as the proxies to be used to capture the magnitudes of these two effects.

\subsection{Spillover Effect}

The spillover effect refers to the interaction between two series. Traditional tourism demand models for international tourism demand suggests that tourism depends on exchange rates and other economic factors, such as the cost of airfares, incomes of tourists, and dummy variable. Tourism demand is negatively correlated with the exchange rate because tourists with higher purchasing power prefer to visit destinations with relatively lower purchasing power. For example, the empirical findings for tourists from Malaysia and New Zealand to Australia show that the memory of tourists of exchange rate shocks could diminish in the long run.

Exchange rates can be significant and have sensible interpretations for the time series of world, US and Japanese tourist arrivals to Taiwan, as well as world prices and two exchange rates, US\$/New Taiwan $\$$ and Yen/New Taiwan \$, for tourist arrivals to Taiwan from the world, USA and Japan, and exchange rates. A strong domestic currency can also have adverse effects on international tourist arrivals to Taiwan.

\subsection{Size Effect of Firm Performance}

The common stock of small firms has, on average, higher risk-adjusted returns than that of large firms. This result will henceforth be referred to as the size effect, or small-firm effect. Firm performance may be driven by firm-specific factors, such as firm size. Several papers have shown that other factors may be more important to firm performance than firm-specific factors, such as demand, technological opportunity conditions, and industry effects. Therefore, it is worth exploring the size effect on the performance of firms in the tourism industry, as well as for Taiwan, as there are many firms of different sizes in the tourism industry.

\subsection{Proxy Variables for Firm Size and Firm Performance}

In practice, stock returns are the most appropriate proxy of firm performance for all-equity firms because a firms' stock price reflects the value of its future earnings, both from existing assets and their expected growth. The literature has indicated that a firm's total assets (TA) can be taken as a proxy for firm size. Therefore, this paper uses two proxies, namely stock index returns for firm performance, and trade market value of total assets (TA) for firm size to explore the size effects on volatility spillovers between exchange rates and tourism firm performance. We will focus on the foreign currencies of the three leading international tourism sources to Taiwan, namely US Dollars, Japanese Yen, and Chinese Yuan.

\section{DATA}

In this section we present the sampling, data grouping, and classifications of tourism stock indexes by the trade market, as related to firm size. Daily closing prices of foreign exchange rates and tourism stock indexes are used for 999 firms from 1 July 2008 to 29 June 2012, obtained from the databases of the Taiwan Stock Exchange (TWSE), Gre-Tai Securities Markets (GTSM), and the Taiwan Economic Journal (TEJ). The three foreign exchange rates associated with the three leading international tourism sources to Taiwan, namely USD/NTD, JNY/NTD, and CNY/NTD, are used in the empirical analysis.

Furthermore, the literature has indicated that the firm's total assets (TA) can be taken as a proxy for firm size. For capturing the size effect on volatility spillovers between exchange rates and firm performance, this paper classifies the tourism stock indexes into two categories, namely Large and Small, by the trade market (a proxy for firm size), which varies according to the requirements of paid-in capital when a public issuer applies for listing. Therefore, the tourism-related firms listed on the market of the Taiwan Stock Exchange 
(TWSE) are defined as large firms (that is, Large), whereas the tourism-related firms listed on the Gre-Tai Securities Market are regarded as small firms (that is, Small). The requirement of a firm's paid-in capital for listing on the Taiwan Stock Exchange is at least NT\$600 million, which is greater than for the Gre-Tai Securities Market, which is at least NT\$50 million, at the time a public issuer applies for listing.

\section{MULTIVARIATE CONDITIONAL VOLATILITY MODLES FOR SPILLOVER EFFECTS}

The two most widely-used models of conditional covariance and correlation in the class of multivariate GARCH models are BEKK and Dynamic Conditional Correlation (DCC). In addition to estimating conditional covariances consistently, the BEKK model can also be used to obtain consistent estimates of dynamic conditional correlations, with a direct link to the indirect DCC model. However, the DCC model does not incorporate the interdependence of different assets in the conditional covariance specification.

Therefore, taking account of the volatility transmission effects across different markets and assets (specifically, exchange rate returns and stock index returns), together with the asymmetric effect, this paper adopts the VARMA-AGARCH model. This specification nests the univariate asymmetric GJR model in modelling the conditional variance process.

The following are the model specifications of the conditional mean and the conditional covariances.

\subsection{Specification of the Conditional Mean}

The multivariate GARCH model is developed to examine the joint processes relating the returns of several different series. There are two series in each portfolio in this paper, namely exchange rate returns and stock index returns. The conditional expected returns equation at time $t$ accommodates each variable's own past returns at time $t-1$ and the returns of other variables that are lagged one period.

\subsection{Specifications of the Conditional Variance}

The BEKK formulation directly imposes positive definiteness on the conditional variance matrix. Specifically, in order to capture the asymmetric effects of shocks on conditional volatility, this paper uses the GJR specification of the multivariate GARCH model and includes an indicator variable for negative returns shocks. The VARMA-GARCH model, a vector autoregressive moving average specification, incorporates volatility transmission effects across different markets and assets under the assumption that negative and positive shocks of equal magnitude have identical impacts on the conditional variance.

However, it is unrealistic to assume that the impacts on the conditional variance from negative and positive shocks of equal magnitude are identical. In order to capture the asymmetric property of differential impacts on the conditional variance arising from negative and positive shocks of equal magnitude, the VARMAGARCH model has been extended to accommodate the asymmetric impacts of the unconditional shocks on the conditional variance, and proposed the VARMA-AGARCH specification of the conditional variance.

\section{EMPIRICAL RESULTS}

This paper examines the size effects on volatility spillovers with asymmetry between the exchange rate returns and stock index returns (which are a proxy for firm performance) using two multivariate conditional covariance models, namely BEKK-AGARCH $(1,1)$ and VARMA-AGARCH $(1,1)$, for modelling the conditional covariance process. The empirical findings of the six portfolios are discussed below. First, we calculate the exchange rates returns and tourism stock index returns as the first difference in log prices, defined as $R_{t}=100\left(\ln P_{t}-\ln P_{t-1}\right)$, where $P_{t}$ and $P_{t-1}$ are the daily closing prices at time periods $t$ and $t$ - 1 , respectively.

The operational definitions of the log return series used in the paper are available on request. Moreover, for examining the size effects on the volatility transmission between the two series, this paper uses five returns series (namely three exchange rate returns and two stock index returns) into six portfolios according to currency and firm size, namely Portfolio 1 (USD/NTD with Large Firms), Portfolio 2 (USD/NTD with Small Firms), Portfolio 3 (JPY/NTD with Large Firms), Portfolio 4 (JPY/NTD with Small Firms), Portfolio 5 (CNY/NTD with Large Firms), and Portfolio 6 (CNY/NTD with Small Firms). Based on the negative correlation of two specific series, this implies greater diversification benefits arising from a portfolio.

\subsection{Graphs and Descriptive Statistics of Returns}

This paper examines the time series data graphically, namely the trends, logarithms, and log differences (that is, the growth rate or the continuously compounded returns) of five data series and the time-varying correlations of Portfolio 1 to 6. The basic descriptive statistics for the five returns series are available on 
request. In terms of exchange rate returns, the average returns of USD/NTD are negative and very low, whereas the average returns of JPY/NTD and CNY/NTD are positive and low. However, both means of the stock returns series (namely Large Firms and Small Firms) have negative and low values.

In general, all of the five series mentioned above display significant leptokurtic behavior, as evidenced by large kurtosis with respect to the Gaussian distribution. In addition, four of the five series show mild positive skewness, with only Large Firms being negatively skewed. The negative skewness statistic implies the series has a shorter right tail than left tail. The Jarque-Bera Lagrange multiplier test statistics indicate that none of these return series is normally distributed, which is not at all surprising for returns data.

\subsection{Unit Root Test of Returns}

A unit root test examines whether a time series variable is non-stationary. Two well-known tests, the GLSdetrended Dickey-Fuller test and the Phillips-Perron (PP) test, are calculated to test for unit root processes. The results of the unit root tests indicate that all returns series are stationary. The unit root tests for each individual returns series reject the null hypothesis of a unit root at the $1 \%$ level of significance.

\subsection{Results of Six Portfolios with BEKK}

All the returns series reveal quite high volatility spillovers (in excess of eighty percent) from its own lags. On the other hand, as the BEKK specification states, the off-diagonal elements measure the cross-market effects, or the volatility spillover effects between the series. According to the empirical findings from Portfolio 3 , for instance, the volatility from exchange returns (JPY/NTD) to large stock index returns (Large Firms) is $34.09 \%$, but the reverse effect (in absolute value) is only $2.56 \%$. This implies that the volatility spillover from exchange rate returns is much stronger than from stock index returns (firm performance).

As noted in the BEKK specification, the significant and positive asymmetry coefficient indicates that negative shocks tend to produce higher volatility in the following period than do positive shocks of a similar magnitude. Some of the estimates confirm the evidence of asymmetry. For instance, in Portfolios 2, 4 and 6, the previous shock transmission from the small stock index returns (Small Firms) affect all the exchange rate returns (USD/NTD, JPY/NTD, and CNY/NTD), but the reverse does not hold from exchange rate returns to small stock index returns.

The individual stationarity conditions of the estimates for all the returns series are satisfied.

\subsection{Results of Six Portfolios with VARMA-AGARCH}

All the return series examined reveal quite high volatility spillovers (of over sixty percent) from its own lags. Followed by the interdependence of volatility spillovers transmitted across markets, the results indicate that there is a significant finding on the returns of large firm stock indexes (Large Firms) associated with both exchange rate returns, whereas the returns of small stock indexes (Small Firms) only affect one set of exchange rate returns. This implies that there is a size effect on the risk interdependence from exchange rate returns to stock index returns (firm performance) for the tourism stock market in Taiwan.

Such an empirical finding arises because the risk associated with each firm size has different transmissions from the three leading international tourism sources to Taiwan. The univariate GJR model is a simple extension of univariate GARCH with an additional term to account for asymmetry. The significant and positive asymmetry coefficient indicates that negative shocks tend to produce higher volatility in the following period than do positive shocks of a similar magnitude. According to the estimates, all the returns of large stock indexes (Large Firms) confirm the presence of asymmetry, whereas none of the returns of small stock indexes (Small Firms) suggest asymmetry.

As the stationarity condition is satisfied for each returns series examined, all the returns series satisfy the second moment and log-moment conditions, which are sufficient conditions for the Quasi-Maximum Likelihood Estimator (QMLE) to be consistent and asymptotically normal.

Therefore, it is valid to conduct standard statistical inference.

\section{ACKNOWLEDGMENTS}

For financial support, the first author is most grateful to the National Science Council, Taiwan, and the third author wishes to acknowledge the Australian Research Council and the National Science Council, Taiwan. 